\title{
From the Supposed Artificial Intelligence - AI To the Accurate Strategic Language - SL
}

\author{
Luis Armando Mojica Castro* \\ Phd student of Universidad de Murcia, Spain
}

Submission: August 14,2020; Published: August 25, 2020

*Corresponding author: Luis Armando Mojica Castro, PHd student of Universidad de Murcia, Calle Baeza No. 6 3E, Spain

Keywords: Artificial Intelligence; Psychological; Cultural; Commercial perspective; Human beings; Sociological; Education

\section{Review}

On this paper, I wanted to share my appreciations, reflections and notes, on a subject that I am passionate about, called: "Artificial Intelligence" - AI, compared to the "certain" programming of Strategic Languages - SL; as a technological illusion compared to the praxis of the consolidation of the order: That is done by an interposed "person" or performer; it is to achieve that a programmed assignment (previously) is consolidated without the responsibility of the intellectual actor being evidenced ... On the other hand, and beyond the technological or commercial perspective, I wish to invite you to assume, with an open mind, somewhat more psychological, cultural and transcendent approaches to determine and confront how artificial intelligence is more a particular way of reasoning for certain "artificial" human beings, oversaturated with logic and incapable of quantum visualizing their nature. You should even doubt the inherent evolutionary factor: from natural intelligence to the artificial and simply assume that it is a mutation that deepens positions of vanity, with which, supposedly, our extraordinary intellectual capacity would be highlighted, which differentiates us from those, supposed, beings less fortunate, intellectually, and incapable of creating tools.

Artificial beings, like artificial intelligence, were not built by human beings in the 20th century; rather, we "conceived" them for many centuries, with a great deal of effort and determination, stubbornly denying our own respect for nature; hence, belittling natural intelligence; which some tribes of yesteryear, both Celtic and American, valued in their harmonious coexistence with other species (Figure 1). Since the 40 's of the last century, $\mathrm{AI}^{1}$ is supposed to be an eminently mechanical and cybernetic subject. I consider that by limiting it so specifically, the intelligence factor has been reduced to seeing it in a mathematical and technically basic way; And therefore, in an effort to place it within a "novel technological" paradigm with wide marketing ${ }^{2}$ possibilities and not stop to study it more thoroughly, we turn it, just, into one more fashion ... (Figure 2). In summary, one of my main concerns is that it is being assumed, very lightly, that artificial intelligence is, only, a way of programming activities in a robot, entity or closed cybernetic system (an additional machine language) ; and therefore, it is assumed that this type of rationality or way of thinking belongs radically to this technological field, and the perspective and its development within even more interesting contexts such as legal, psychological, community is lost. , the sociological, educational and philosophical, among many others, that the limited mechanistic marketing ... For this reason and to motivate the realization of psychological, anthropological and sociological projects (interdisciplinary) that I see as the human species together with this type of reasoning or functional anticipation that, for now, we

1943: Walter Pitts and neurophysiologist Warren McCulloch presented the first AI research paper

${ }^{2}$ All technological development opens an important market niche and product skimming through which significant profits are guaranteed. This market is a novel source of resources that can be aligned or managed jointly from a brand (behavior concept) to integrate: household appliances, cars, domestic and industrial tools, regional, national, international, space travel, (of course) pharmacists, obviously investigative and educational; And the brand that sticks to this kind of future will gain a lot of economic power. All supported by psycho-technological paradigms (marketing) because the idea of complementing that old image of a person by the pool with a glass of some type of alcoholic beverage is very powerful and now seeing yourself sharing with other types of beings or to dominate other types of beings to make them our servants; it is a basic social regression to slavery in which vanity plays an egotistical role; Therefore, the market, according to this advertising, would put at your disposal, not only an individual who serves to give you all kinds of services, but also allows you to reaffirm your authority and worth. That is why some people acquire a pet, a booming market for the "adoption" of animals; with what they project which is to share love; and it is evident that they only want to have someone to dominate, command and consume; or someone who being dependent allows them to feel necessary or important ... Of course, there will be those who really "love" them and others who for this love (when the fashion passes) will abandon them ... 


\section{Global Journal of Archaeology \& Anthropology}

call: AI, it can be nurtured and enriched, if We promise to risk going deeper into more complex levels, within the parameters of social behavior; in which behavioral perspectives are included such as instinctual, rational, autonomous, automatic, reactive, natural and, of course, artificial (Figure 3). From an initial perspective, to get to qualify if the machines are intelligent or not; or if the reprogramming or functional transfer by copying the language of the way humans give solutions to "their problems" make them, at most, skilled servants; This is why we must definitely see the results from the background context that generates them (their cause): Why do beings with AI act? To guarantee their criteria of independence, "freedom" or existential autonomy as individuals? Perhaps: Do they know they exist?

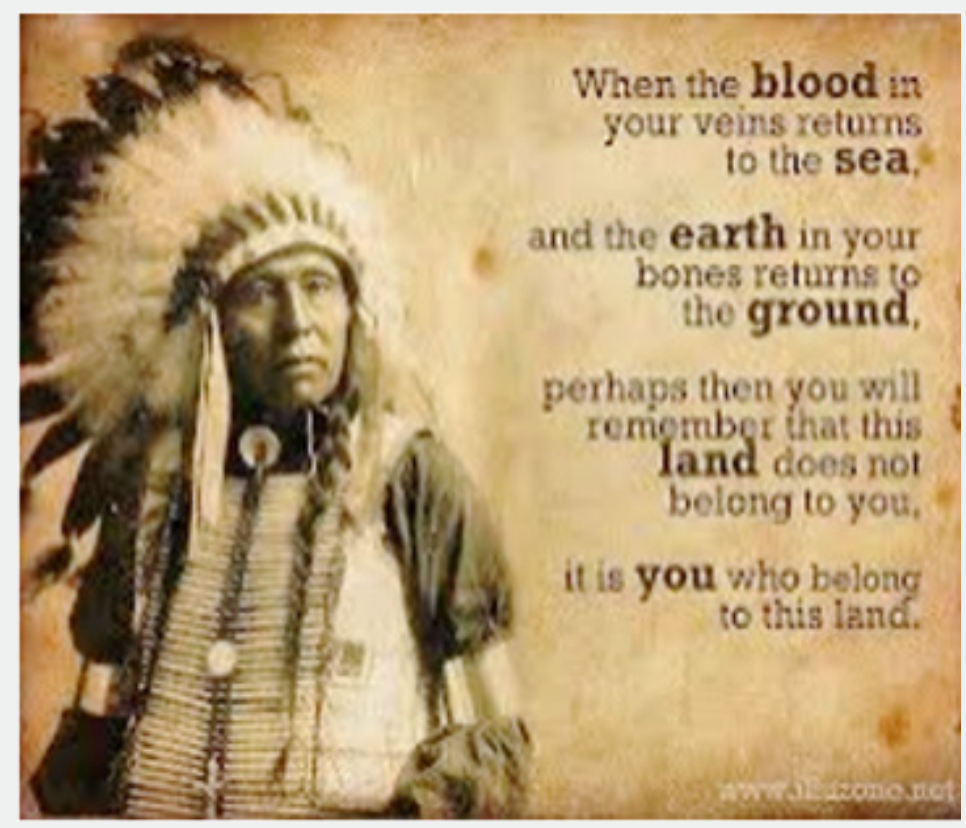

Figure 1: Letter from Chief Seattle.

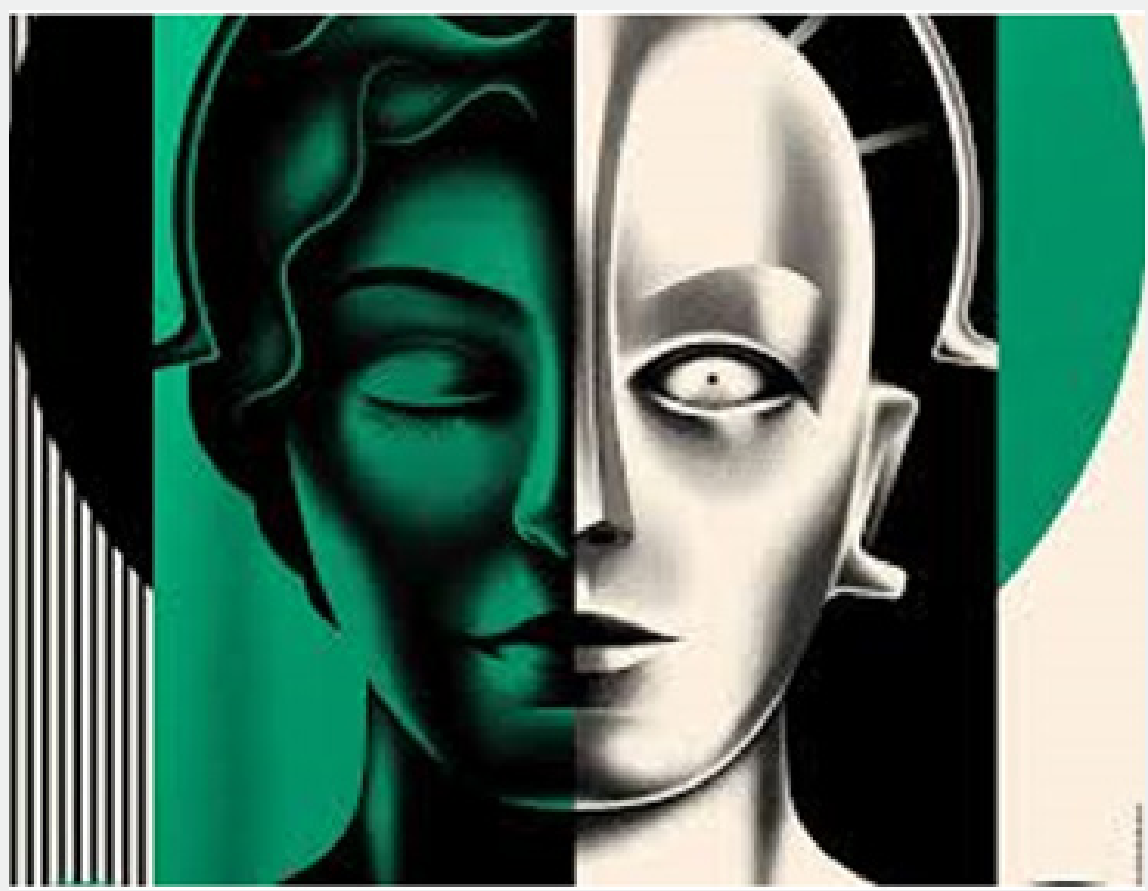

Figure 2: Very lightly, that artificial intelligence is, only, a way of programming activities in a robot, entity or closed cybernetic system (an additional machine language). 


\section{Global Journal of Archaeology \& Anthropology}

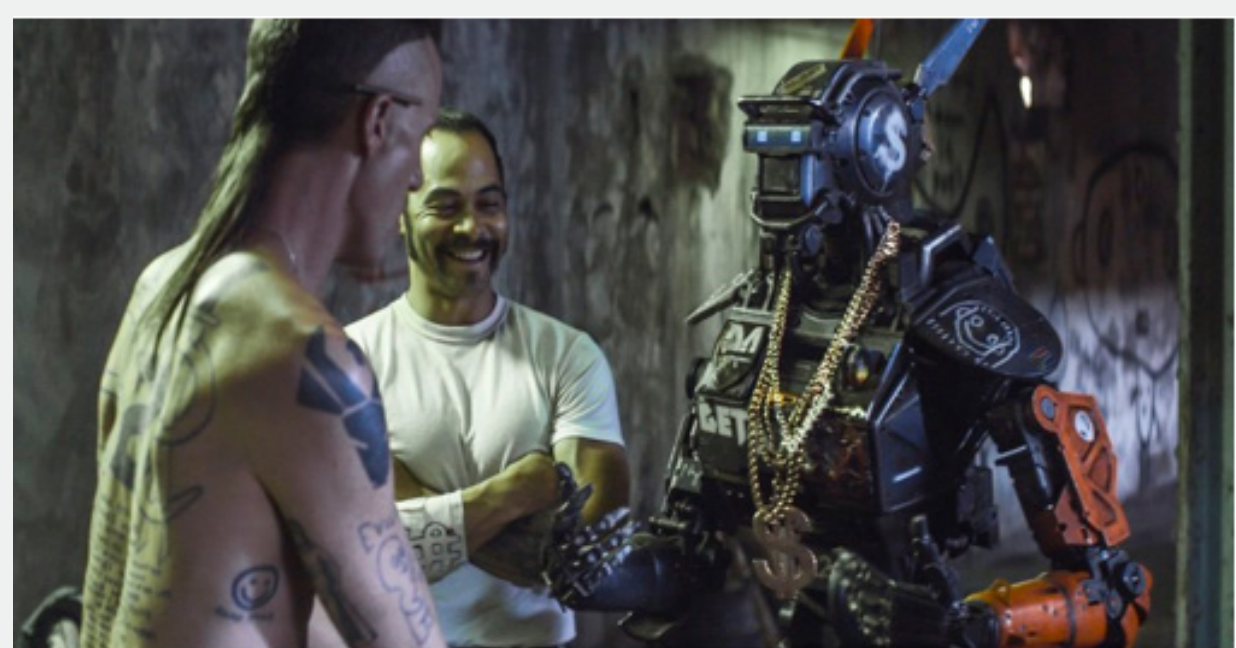

Figure 3: From an initial perspective, to get to qualify if the machines are intelligent or not; or if the reprogramming or functional transfer by copying the language of the way humans give solutions to "their problems" make them, at most, skilled servants.

Let's take a brief perspective on the reason that species (or at least ours) have to develop intelligence; According to Llinás [1], in books like The Brain and the Myth of the Self ${ }^{3}$, he states that intelligence emerges in living beings due to the need to analyze a complex situation; Similarly, Gary Kasparov ${ }^{4}$, being more forceful, suggests that it is the ability to anticipate ourselves to anticipate a result, fundamentally, to guarantee its survival or the integrity of itself. In other words, in advance it is capable of virtualizing its own functionality or action, which, as a biologically autonomous (living) being, incurs to maintain itself consciously existing, in such a way that said survival depends on itself and does so in an ordinary and daily way. On the other hand from the artificial, and it is really curious, since it seems that it is called artificial because, in reality, it does not solve a problem "of its own" (but of another's); which, through work groups, virtualizations of probable events that would affect humans, legal application of socio-cultural contexts and through legal protocols and mathematical formulation, the ability is transferred to it, by "commission" (programming of tasks), so that a probable solution can be solved or given to a functional problem unrelated to who solves it; since the legal person or the machine has no problems, no functional sense of its own or from itself (its self). In which case the term is not artificial but alien, cloned, virtualized, transferred, commissioned or task. If it is called AI because, apparently, it can solve a problem that it "faces" (Figure 4). There are two perspectives, regarding the artificial, in the same way calculators do it when faced with a sum or any conditional event that has already been formulated since before the so-called programming; on the other hand, when a parrot repeats a phrase, an animal protects and breeds an animal that is not of its species or when it generates a hunting strategy ... we do not call it intelligence. Human beings like animals solve problems (our problems...!), Machines don't... but they are used through programming to solve "our problems" (outside their interests, if they had them) efficiently and effectively. It is by these two terms that the machine manages to be so usefully valuable for humanity, because since manufacturing and later industrial fashions, efficiency has been the goal to produce at a lower cost; and efficiency, since it guarantees to repeatedly multiply a function, result or object, but neither of the two makes them intelligent; because intelligent is the one who discovers the problem to be solved efficiently and effectively. Precisely, It is important in a subject like this: "intelligence", to be prudent from the beginning in order to certainly assume a consistent meaning proper to a serious cognitive field; so as not to end up saying "scientifically" nonsense (contradictory phrases that cancel out in their own structuring by going beyond the rational capacity of the person who pronounces them; the elderly said: "speak without thinking") such as: the "empty field loaded with particles "; the "origin of the universe", when we assume that there are dark foci without time; the "intelligent life" to assume that whoever does not think like

${ }^{3}$ According to Llinás, intelligence is based on self-awareness ... problem of unreliability of computing in analog systems. Probably, with suitable functional architectures, it would be possible to generate awareness in numerous non-biological entities.

The second problem is the knowledge of the "self". Suppose that a certain materialization of consciousness is given enough freedom to explore and internalize the external world, so that it implements an image of itself, however primitive it may be. While this materialization may evaluate external reality, it is likely never to have a conscious entity in the human sense. We know that this is fundamental for the functioning of the nervous system" (Llinás, 2003).

${ }^{4}$ Gary Kasparov, world chess champion: "Intelligence is anticipation. It is also the ability to analyze a situation and make the best evaluation to prepare the best shot. (...) Society today does not resort to our intelligence. We are bombarded with information that prevents us from reflecting and makes us passive". https://www.semana.com/vida-moderna/articulo/que-es-la-inteligencia/24892-3 
the speaker is clumsy, animal, vegetable or a rock ... and without going so far, not as light as the advertising messages, in the style of: "the Human Being is a be logical, if you are hungry eat". I think you don't need to be "so human" to assume that you don't need to be logical for that (Figure 5). To know in depth what we are talking about, you have to initially think from the original and epistemological senses of intelligence and its qualifier: artificial. We know that everything that exists on this planet is something natural, created with (and for) nature itself; However, given the Human Being's obsessive admiration for differentiating itself from the "ordinary" nature of the planet, we have been taught that we are cultural beings, that is, we create our own particularizing environment that virtualizes social life. We assumed that we were the only beings, that as a species, we had this "rational" advantage and we formulated it by affirming that we are creators of tools $s^{5}$... Well, we continue, the creation or virtualization of a functionally specialized environment leads us to assume a consequent particular spatio-temporal structuring (factor observed in the other species, but for now let's leave that point there), a field of its own and special for those who build it; and in the human species, this field is called culture (Figure 6).

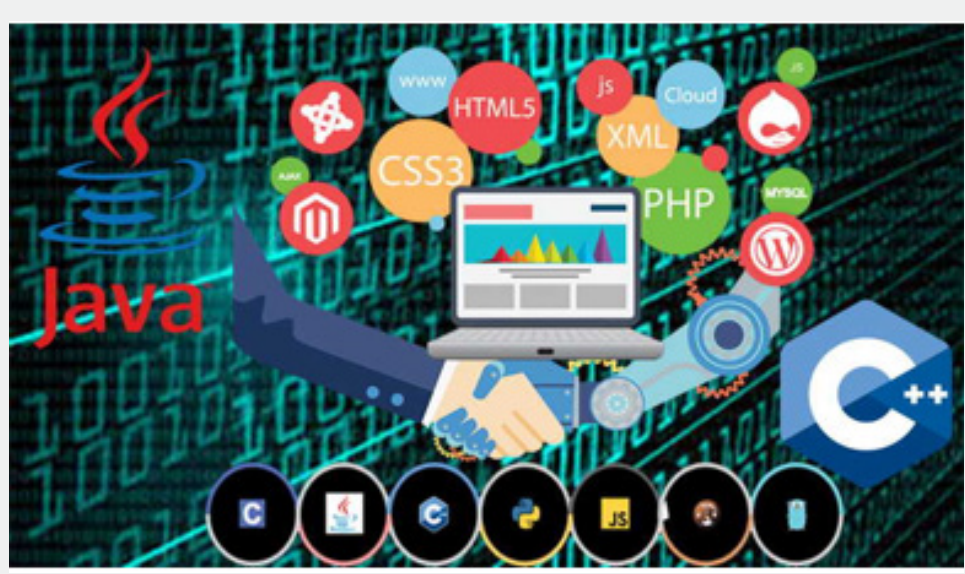

Figure 4: If it is called Al because, apparently, it can solve a problem that it "faces" ...

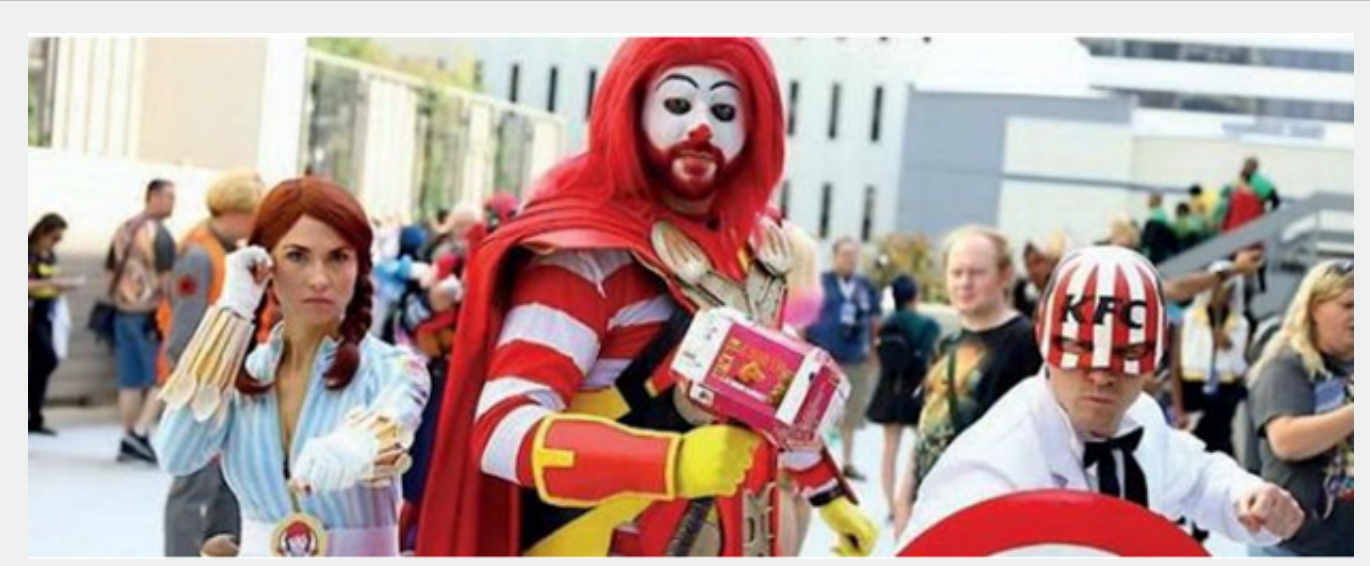

Figure 5: To know in depth what we are talking about, you have to initially think from the original and epistemological senses of intelligence and its qualifier: artificial.

It is not really known which was first if: culture, which could have occurred in a proto-cultural way from the species that preceded us, or the Human Being; since many affirm that we are "intelligent" or creators of our own and unique rationality (functionally differentiating); And there is the point ... whoever is the first, the cultural factor is proper and particular to human

${ }^{5}$ Which is no longer so evident because we know many examples of species not so self-centered that have created formidable tools and weapons that centuries or better millennia ago surpassed the imagination of the Human Being and in most cases we have copied their abilities, natural and artificial. : The bat with its natural ability to sound, the sperm whale that shoots a sonic wave to stun its rival(usually the giant octopus), the lobster that with a click generates a void space and creates a laser that affects its victim, there are birds and certain kinds of insects that keep slaves and servants, etc. In short, our cultural process only differs from that of animals within our limited and self-centered scientific perspective; But without so much ego, nature has many millennia ahead of us. 


\section{Global Journal of Archaeology \& Anthropology}

beings (it does not work or makes sense for planetary nature, on the contrary it perverts it), then it would no longer be natural, therefore It is definitely artificial ... And that means that artificial intelligence is called in this way, not because of the creation of engineers transferring other people's problems but, because it was a way of thinking and rationalizing that evolutionarily was created by the same Being Human for many centuries; or, paradoxically, created by the same culture. So if culture has been created by man, it is artificial; However, if culture was the forerunner of man, it would be natural and, therefore, intelligence as well, and the latter would not then be the monopoly of the human species (consequently, we would be more animals than we are willing to accept). For many thinkers or intellectuals it is completely evident that: "the Human Being thinks artificially" the rest is instinct; responding to the advertising discussed in previous lines, seeking to feed is not a logical function, even plants do, but developing logical processes to solve in a virtual and efficient way natural problems in advance, that would be artificial intelligence; or to solve problems that do not exist in the present but that, due to having faced them in the past, have degrees of probability of reappearing in the future, that would be: being artificial and even vain. Intelligence is a rational function of anticipating the need to protect oneself, from instinctual factors; but artificial intelligence - AI is anticipating for reasons other than instinctual, it is "problematizing" for the simple pleasure of knowing, thinking or idealizing; when a woman or a man for their vanity "problematizes" to seek a beauty that does not seek to satisfy another or achieve a conquest, but only to assimilate to a social judgment called fashion ... that is artificially "problematized" ... it would already begin to be intelligence artificial, perhaps a very paradoxical intelligence; but that is very artificial. But the focus of intelligence is the same, when we "overcome" instinctive symbiotic processes to accumulate food or "scarce resources" and replenish ourselves, avoiding continuing or, worse, breaking natural cycles, we are artificially intelligent, we apply unnatural intelligence, so that any company or corporate unit that is legally called a Legal Person, operates and manages artificial intelligence: "it has been created to solve cultural problems, fundamentally like any machine that impersonates the person interested in solving or carrying out a task (Figure 7). Intelligence according to its specialized cognitive environment, from before Bacon ${ }^{6}$ [2] \& Hume $^{7}$ [3] to our neuropsychology ${ }^{8}$, is a faculty to develop cognitive processes such as: learning, understanding, associating, comparing, reasoning, discerning and abstracting information to solve problems (cultural and human). More from the malice of the twentieth century, evidenced in the destruction of their habitat; and before the vision of the new quantum currents that shows the denial to see our environment, I prefer to understand that intelligence is a natural function to be aware of its systemic integrality (one in its midst) that instinctively allows it to assume a sense of benefit or sacrifice for "himself" in balance with his environment or his offspring; in a similar way to the holistic symbiosis they present in their mammalian behavior.

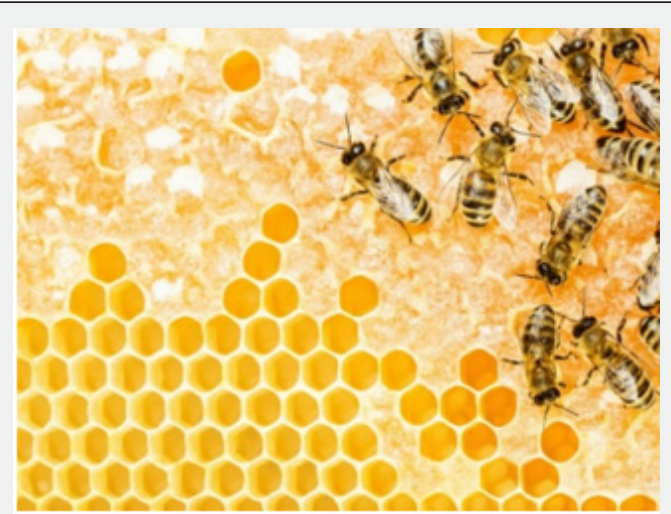

Figure 6: The Human Being: since many affirm that we are "intelligent" or creators of our own and unique rationality (functionally differentiating).

${ }^{7}$ In contrast to the extraordinary and abstract, Hume assumes a naturalistic position, on intelligence... "Only when faced with the discovery of extraordinary phenomena, such as earthquakes, epidemics and prodigies of any kind, they do not know how to assign an adequate cause and explain the way in which the effect is produced by her. It is normal for men, in similar difficulties, to resort to some invisible intelligent principle, as the immediate cause of the event that surprises them and that, they think, cannot be explained by the common powers of nature. But philosophers, who carry their investigations a little further, immediately perceive that, even in the most familiar events, the energy of the cause is as little intelligible as in the most unusual and that we only learn from experience the constant conjunction of objects, without ever being able to understand anything like a connection between them. At this point, then, many philosophers consider themselves obliged by reason to resort at all times to the principle to which the common people resort only to times that seem miraculous and supernatural. They recognize that the mind and intelligence are not only the ultimate and original cause of all things, but also the immediate and unique cause of every event that occurs in nature. They claim that the objects that are normally called causes, in reality, are nothing more than occasions, and that the true and immediate principle of all effect is not any power or force of nature, but the volition of a supreme being who wants certain objects are forever linked together. "(Hume 1980)

${ }^{8}$ Types or classes of intelligence Gardner, for now there are 9 without counting the artificial. 


\section{Global Journal of Archaeology \& Anthropology}

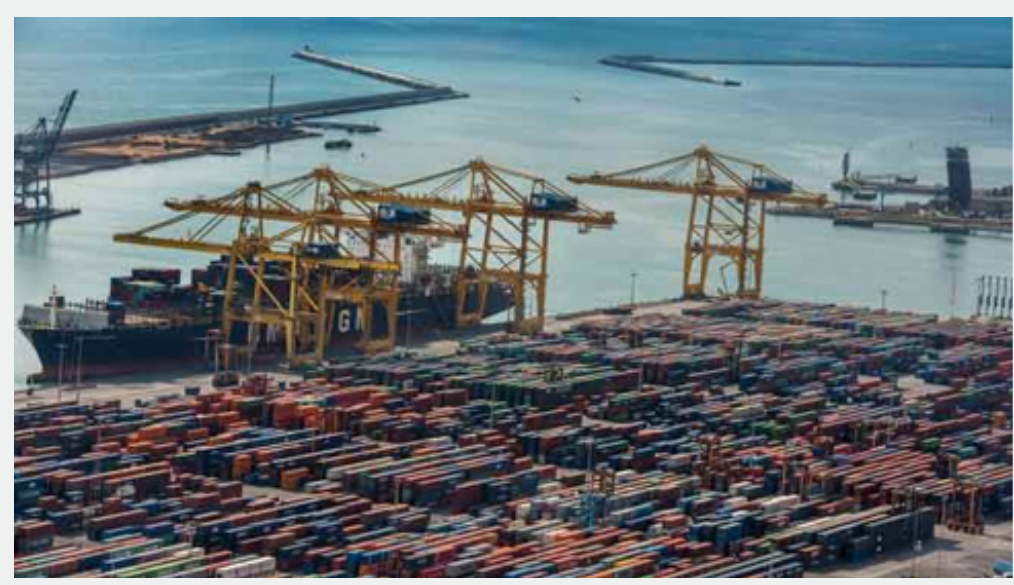

Figure 7: A similar way to the holistic symbiosis they present in their mammalian behavior.

On the other hand and returning to a pragmatic sense, every engineer knows the difference between data and information, when a parrot speaks, it delivers data not information, that this noble animal can "speak" and repeat pre-programmed ideas by repetition does not make it intelligent, but it does able to repeat data outputs at certain times ... Similarly, Gardner atomizes intelligence into multiple "abilities"; From this deductive process it would be obtained that what is installed in a computer is not intelligence, it is fundamentally a language, efficiently structured; and it would be in the best of cases a Strategic Language - SL of processing to compare, associate, "reason and abstract", data not information; since the latter is realized as such when it assumes a meaning and this is only defined by the Human Being. Meanwhile, computing units such as companies, which are legal entities, make decisions alone, on request (such as a trust), to affect human beings, it is clear that legal persons are not motivated by the bursting of the stock market of values, to natural persons yes; I would even say that computers are striving to deliver the digit that shows bankruptcy, but that does not excite them (Figure 8). If it is true, obviously, there is a way of thinking in a natural way, (perhaps called: common sense); but in most cases, especially at logical levels with meaningful reasoning, one gets to think artificially or artificially to process thoughts or activities in advance, a particular and very human way of processing. Therefore, this reiterates that artificial intelligence has been developed for millennia; and that it is not a particular language of cybernetic systems for robots or solely developed by processor companies. It is the way in which artificial, imaginary and / or legal people think or solve "their problems". AI is one of the most typical and customary ways of thinking of human beings, which was evidenced in the creation, development, automation and systematization of legal entities ${ }^{9}$ (Figure 9-10). This way of thinking, with a linear sense, initially, is what we want to transfer to the memory processors of cybernetic systems; but it is not created at the time of assembling it or "translating" our way of thinking about machines ... becoming, then, an ability of the CPU that really is: Strategic Language - SL, in fact the language, itself, it is a form of processing; We could say that the execution carried out by the robot, by SL, is a virtualization of a human order (protocol) to strategically develop it at a later time. This alternative processing, SL, has been developed and evolved by the human species; What happens is that we are in a novel moment, given the use of cybernetic systems that allow us a way to contrast our own language with a system that replicates it; and thus to show that in our mind (individual and collective) there are virtualizations of the natural that go beyond the natural border and therefore show its state of artifice or artificiality; that is, it is strange to nature. Perhaps that is why for certain cultures, civilizations or societies we are strangers to nature and we do not function symbiotically with this planet or its natural way of life (Figure 11).

\section{Conclusion}

I consider that: The challenge is to know if we are still capable of keeping an open mind, and not increasingly closed and specialized, because AI cannot stay open and less like a mind ... What is installed in robots or closed cybernetic systems is not an intelligence, from the neuropsychological point of view; what happens is that the word "Intelligence" is used because it has been highly revered and has become a very effective language tool for marketing strategies ... What is installed as software in closed cybernetic systems is a Strategic Language - SL. Humans took millions of years to develop what we manage as such, since it is the fundamental tool to develop culture as a functional environment of the community. SL: It is a functional integration

${ }^{9}$ It could even be said that every type of government that represents a community, such as the republic, is an artificial intelligence; however, that is the point, an empire is a natural intelligence of government and dominion...; well, we could doubt if it is intelligence; but not that it is very natural ... 


\section{Global Journal of Archaeology \& Anthropology}

that transfers the human communication code (evolved) to the communication structure of electronic and mechanical resources (cybernetics) to obtain functional results, with a unique meaning for humans; that is, cultural. I consider that intelligence is a faculty that more than remembering and associating can imagine; that is, to inhabit multidimensionally, without time; so man is not yet ready to create intelligence, this faculty is, for now, typical of organic beings ... Artificial intelligence would become another type of intelligence, according to Gardner's parameters, a specific, highly strategic and cultural factor of the abilities to solve human problems; the one that developed and evolved from millennia ago, since human beings have been transforming ourselves into artificial beings (of artifice or strategic mind), because that is how the planet had projected it; and that is why our particular means of virtualization (environment) has been specified in an ethereal concept to assimilate and interpret the reality to be shared, called: culture. Artificial Intelligence would be based on the specialization of the experiential function; while the natural, in dimensional integration in the face of the non-programmable or unknown.

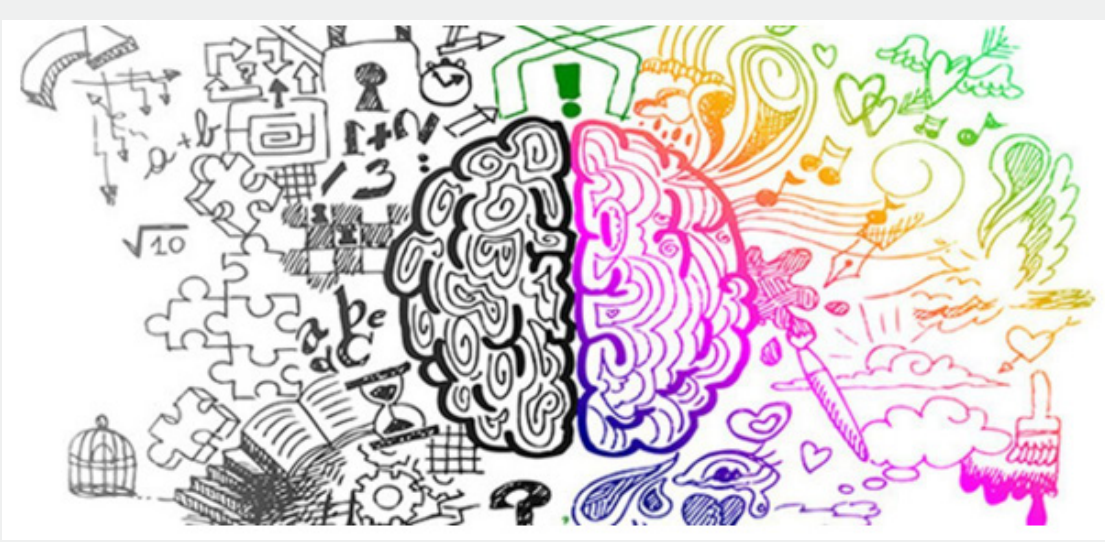

Figure 8: Multiple Intelligences and emotional intelligence.

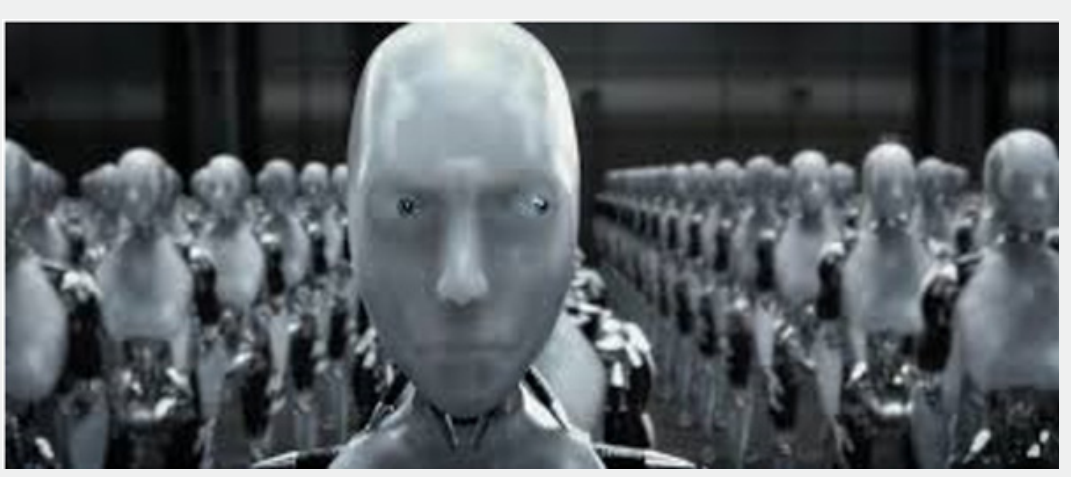

Figure 9: $\mathrm{Al}$ is one of the most typical and customary ways of thinking of human beings, which was evidenced in the creation, development, automation and systematization of legal entities.

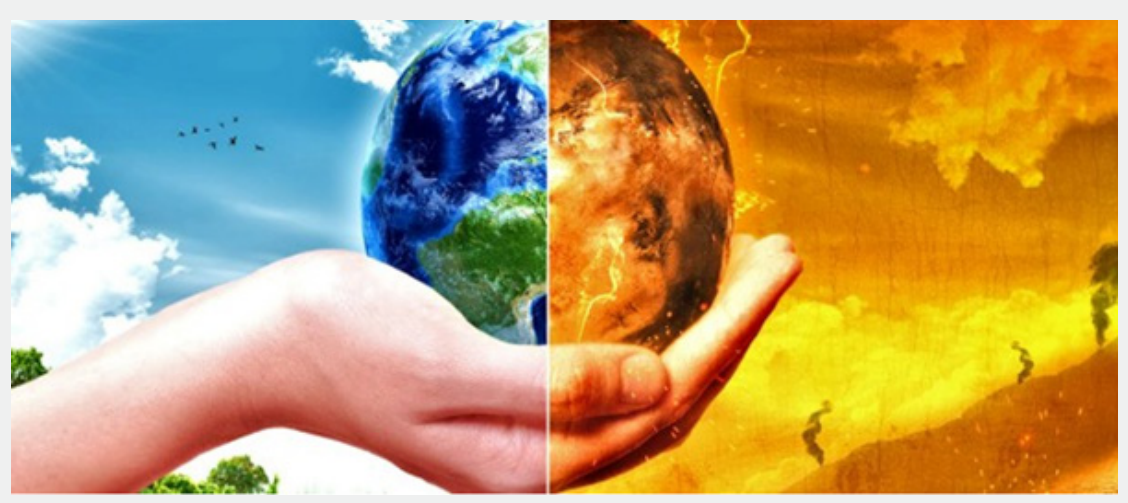

Figure 10: SL, is a virtualization of a human order (protocol) to strategically develop it at a later time. 


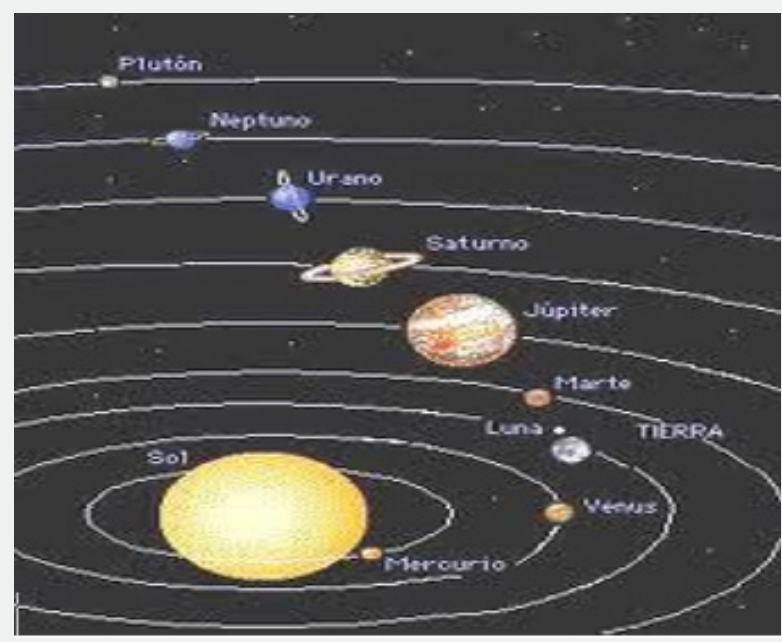

Figure 11: Intergalactic mythical beings ... They give meaning to our existence.

Beings with mineral-based structures (mainly: metallic) are intergalactic, inhabitants of space, practically eternal for interplanetary cycles; They are responsible for interconnecting the worlds (for example with water), with different types of planetary species with other similar worlds.

\section{References}

1. Bacon F (1878) Novum organum. Clarendon press.

2. Hume D (1980) Research on human knowledge. Alianza Editorial, Madrid, p. 94 - 95.
3. Llinás RR (2003) The Brain and the Myth of the Self: The Role of Neurons in Human Thought and Behavior. Editorial Norma.
This work is licensed under Creative Commons Attribution 4.0 License DOI: 10.19080/GJAA.2020.11.555818

\section{Your next submission with Juniper Publishers will reach you the below assets}

- Quality Editorial service

- Swift Peer Review

- Reprints availability

- E-prints Service

- Manuscript Podcast for convenient understanding

- Global attainment for your research

- Manuscript accessibility in different formats ( Pdf, E-pub, Full Text, Audio)

- Unceasing customer service

Track the below URL for one-step submission https://juniperpublishers.com/online-submission.php 